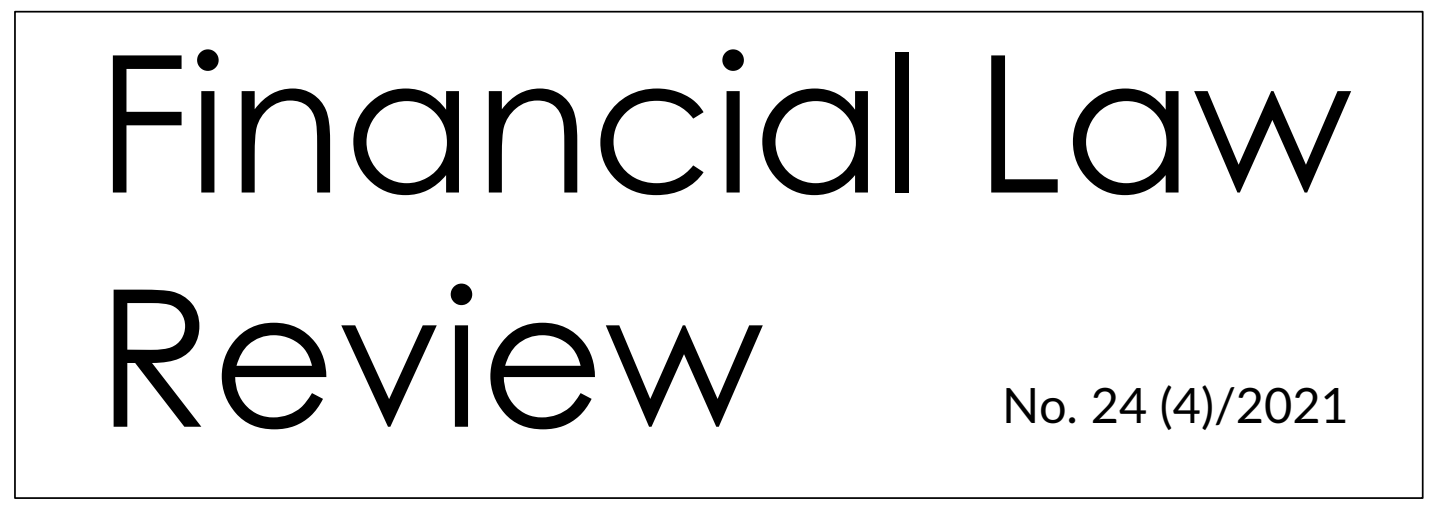

UNIVERSITY OF GDAŃSK • MASARYK UNIVERSITY • PAVEL JOZEF ŠAFÁRIK UNIVERSITY • UNIVERSITY OF VORONEZH http://www.ejournals.eu/FLR

\title{
DAMIAN CYMAN* \\ THE CUSTOMER AS A SUBJECT OF PROTECTION ON THE FINANCIAL MARKET IN EUROPEAN UNION
}

\begin{abstract}
The crisis begun in 2007 exposed the weakness of the existing regulations, revealing challenges for legislators all over the world. Financial stability started to be understood as an essential value for the proper operation of the financial market. It has become important to address the question as to how to protect financial markets from more crises, or at least alleviate their effects. The idea of supervision of a financial market has undergone thorough transformation. Particular emphasis has been placed on protecting buyers of financial services. Adequate customer protection has been recognized as a sign of trust in the market and its stability and has gained systemic importance and relevance for the European financial system.
\end{abstract}

There is a growing tendency to enlarge the group of subjects eligible for special protection. it is becoming an increasingly common idea that not only consumers but all non-professional customers should be protected. The idea is becoming widespread that the weaker party to a legal transaction can be not only a consumer [natural person] but also a non-professional market entity. Such a solution is certainly appropriate. Narrowing down the 'consumer' to a natural person may seem artificial and out of line with market realities, not to mention the serious consequences of bad financial decisions taken by non- professional financial market participants.

Another important challenge facing the modern financial market is to establish a system of institutional safeguards to ensure security for all market entities and to enforce fair play rules. However, even the best provisions of substantive law, though necessary, may prove to fall short.

${ }^{*}$ Faculty of Law and Administration, University of Gdańsk, Gdańsk, Poland.

Contact e-mail: damian.cyman@prawo.ug.edu.pl; ORCID: 0000-0002-1443-8981. 
Therefore, there is a pressing need for strong and competent both state and international institutions duly equipped with auditing and supervisory powers to deal with the present situation. They should also have the possibility of enforcing substantive laws in a way that allows for flexible responses to any emerging threat to the protected values.

The shift towards a regulatory and supervisory method of protection sets a more serious tone for the supervision model adopted for the financial market. In it, the market is responsible not only for ensuring that the supervised entities operate correctly, but also for the quality of services that they provide.

Key words: Financial market, consumer protection, financial stability, financial services, financial crises.

JEL Classification: K22

\section{Introduction}

The financial market has benefited from dynamic technological growth, improving its efficiency and range of services. On the other hand however, the market has become more complicated, as have the links between market entities and services provided. The ensuing situation is one, in which entities involved in the financial market, including customers, are sharply growing in number, but with no corresponding rise in the awareness of factors impacting market operation, the nature of services or consequences of such services for their recipients. The crisis begun in 2007 exposed the weakness of the existing regulations, revealing challenges for legislators all over the world and providing the impulse to redefine financial stability [Canova 2009].

Financial stability started to be understood as an essential value for the proper operation of the financial market, as a common good which should be preserved. Stability is defined as a condition in which the financial system performs its functions in a continuous and efficient manner even when affected by unexpected and adverse disruptions of a significant magnitude [Shinasi 2004]. The stability of a financial system is not a natural consequence of its operation. When it is disturbed, it can only be restored by a heavyhanded and enormously expensive intervention of the authorities. It has become essential to address the question as to how to protect financial markets from more crises, or at least alleviate their effects. The idea of supervision of a financial market has undergone thorough transformation. A blueprint has been proposed for a new system of market security within the European Union and on a global scale. It has become one of the priority policies for both individual member states and the EU as a whole to protect the financial system from destabilization, which might disrupt the operation of the economy. A series of 
changes, some of them dramatic, has been applied to the way in which markets are regulated. This has also required an axiological redefinition of these regulations, including in terms of establishing mutual relations between public authorities and financial institutions and between these institutions and their customers. Particular emphasis has been placed on protecting buyers of financial services. Although the area of consumer protection has been regulated in European Union since 1987 [EPRS 2015: 4], the global financial crisis has highlighted the importance of consumer protection and financial literacy for financial stability. Adequate customer protection has been recognized as a sign of trust in the market and its stability [Moloney 2015; Akinbami 2011]. Thus, customer protection has gained systemic importance and relevance for the European financial system.

The objective of this article is to discuss the need for redefining the object of protection on the European financial market. The existing consumer protection is thought by the present author to be insufficient to restore trust following the last crisis. With trust being a key to financial stability, consumer protection should be extended to include other nonprofessional customers. Narrowing down the group eligible for adequate protection may give rise to another financial crisis in the future, especially considering the fact that the latest post-crisis regulations have been predominantly designed to ensure the continued operation of institutions under unstable financial conditions. It should be inferred therefore that a change in approach to the financial market's active subjects is inevitable and necessary. It determines whether the much-needed balance can be reached between nonprofessionals and professionals specialized in providing financial services. Protections should not be intended to privilege the customer but to restore balance between highly professional financial institutions having expert knowledge and their customers relying in their decisions on the information provided by those very institutions. However, assuring equal opportunities cannot be limited only to providing non-professionals with better access to information held and generated by their service providers. A more profound intervention of state authorities with supervisory powers seems to be necessary. They should be tasked to show concern not only for financial market subjects, especially those under supervision, but also for the services offered on the market.

\section{The system for protecting consumers of financial services}

The system for protecting a customer of financial services is a set of interrelated institutional and procedural arrangements as well as provisions of substantive law with the overarching aim of assuring an adequate level of security to customers and - more broadly 
- to all financial market entities. This objective will not be met by privileging one of the parties, but by restoring balance in terms of information possessed by all financial market entities to compensate for gaps in their knowledge and prevent the customer from bearing excessive risk [Benohr 2018]. The basic aim of protection is not to stop customers on the financial market from entering into disadvantageous deals, but to make possible conscious decision-making with access to full information in a market free from fraud and abuse [Rösler 2010; FSB 2011]. Financial literacy can contribute considerably to financial market stability [OECD 2009], however, as financial markets have become more complex, consumers often lack the understanding of financial products and overestimate their knowledge leading to unsuitable decisions, in particular for vulnerable consumers. The customer protection system should avert panic on the financial market and eliminate the so-called infection effect whereby an often concealed risk is transferred to the market entities. Restrictions should also be put on risky and sometimes aggressive sale of financial services for the exclusive benefit of a financial institution or persons employed by it, at the expense of the customer's equitable rights and interests (moral hazard).

The customer financial system is one of the essential components of a financial safety net designed to preserve financial market stability. The system should be effective, which means addressing each area of concern, while at the same time preventing a conflict of powers. The institutions making up the system should be granted adequate powers, including to authoritatively intervene into each market player's activities, but at the same time respect free-market principles, including the freedom of commerce and contracting.

The customer protection system in European Union is evolving and its shape is changing constantly. This happens as the system soaks up experience from the national, European and world markets. It should also adapt to new conditions, including those caused by technological changes as well as the emerging market segment known as FinTech, Artificial Intelligence and the challenges that come with it [Arner, Barberis, Buckley 2016; Lui, Lamb 2018]. It is also correlated with the pan-European protection system, particularly with respect to consumer law.

The crisis of 2007 undermined the axiological assumption of consumer rationality. Behavioral economic studies have instead indicated that humans are heavily influenced by 'framing effects' and may struggle to make rational decisions [Ramsey 2015]. Customers were often seen to act irrationally even despite having all the necessary information, making decisions based on emotions rather than economic sense [Mak, Braspenning 2012; Lefevre, Chapman 2017]. It has been found to be necessary to scrutinize financial stability with regard to the mutual links between financial institutions and the increasing systemic 
risk over time. Far from being neutral for stability, the business model adopted by financial institutions and the corporate order, including salary terms, actually generate significant risks, especially in mortgage loans [Cyman 2016]. This has given rise to a new paradigm of regulation and supervision based on the assumption that the financial market is unstable and pro-cyclic, with market entities displaying a tendency to irrational actions driven by a herd instinct. The instability is compounded by the complexity of financial systems, business models and financial innovation. The paradigm has as its core component the limitation of and combat against systemic risk.

This has brought into prominence the supervisory institutions shaping the legal conditions in which consumers operate. Legal regulations determining the extent to which these institutions affect the financial market are equally important. It is now among the core challenges for a modern state to coordinate such institutions into a system providing adequate protections for all market entities and safeguarding their fair conduct. However, even the best provisions of substantive law, though obviously necessary, may prove insufficient, partially because of the consumer's lack of knowledge about how the financial market operates. In that respect, it is necessary to promote financial education in society [Rutledge 2010]. Another reason is unawareness of rights and obligations [Ciacchi 2010]. The gap can be partially bridged through a legally prescribed duty to provide information necessary for an informed decision [Porras, Boom 2011]. However, it could be asked at this point if the customer should have good information on a bad deal or be entitled to a good deal. In addition, information per se is not sufficient for an individual to make rational decisions; the way it is presented is also crucial. Now, as we shift away from the idea of people as rational beings acting in a logical and economically reasonable manner and in reliance on information, towards one in which people are more emotional than calculatinRational g, driven by instant gratification [money in hand] rather than wary of the cost burden [high cost of borrowing], it is necessary to have in place strong and competent authorities with adequate inspective and supervisory powers to handle the situation properly. A provision should also be made for enforcement of substantive law so as to respond flexibly where protected values are likely to be compromised.

The transition to a more high-profile model of regulatory and supervisory protection of the financial market comes with more responsibility, not only for the proper operation of supervised entities, but also for the quality of the services they provide. EU laws do not provide any specific guidelines as to which model of financial supervision should be adopted, leaving this at the discretion of the individual member states. However, there is a notable growth in interest in twin peaks supervision based on two tiers and two bodies of 
supervision. One of these, usually a central bank, is responsible for stability and cautionary supervision over financial institutions, while the other - for providing services and customer protection. Integrated supervision indirectly adopts synergy of supervision of financial institution and customer protection. Twin peaks supervision considers the fact that protecting the financial market from destabilization and customer protection may potentially stand in contradiction, which means that they should not fall within the powers of the same authority.

\section{Customer definition}

The layman's definition of 'customer' varies depending on the context in which the term is used. 'Customer' in its narrowest sense is identified with 'consumer'. In the broadest sense, the word covers all entities, regardless of their legal form or nature of contracting, that acquire financial products and services on the market. As the variety in meaning precludes any precise scientific treatment, the term can be divided into three basic groups: consumer customer, non-professional customer and professional customer.

\subsection{Consumer customer}

Legal theory has not developed a consistent definition of 'consumer.' The term derives from economics, where a consumer is the end-buyer of products or services for personal needs. A natural person on the financial market who enters into a contract for purposes unrelated to his commercial, economic or professional activities is deemed in principle to be a consumer. As for Community law, EU directives individually specify this term depending on the scope of regulation but shared features include attributes as to subject (natural person) and the consumerist nature of the contract (no link with commercial activities against payment). This definition is used in many Directives [Directive 93/13/WE, 2005/29/WE, 2008/48/WE or 2011/83/UE]. In some cases, member states may exercise the so-called national option to extend this term with micro-enterprises.

Some legal acts single out from among consumers an extra category of people of limited means or endangered with social exclusion and therefore in need of special protection [Directive 2014/92/EU]. The reason why this group has been singled out is that they are more often than others prevented from using the banking system or their access to it is restricted. That is why they are forced to use other and usually very expensive sources of funding [e.g. high-interest short-term loans]. In their case, protections should address these 
particular areas of activity of financial institutions or - alternatively - facilitate access to basic banking services. Also noteworthy is the concept of 'average consumer', one who is well-informed, attentive and cautious. The average consumer is evaluated based on social, cultural and linguistic factors, as well as his belonging to a specific consumer group.

\subsection{Non-professional customer}

The idea of a non-professional customer contains within its scope entities with a legal personality or organizational units without legal personality but entitled to assume rights and obligations in their own name, as long as the contracts they conclude are not directly related to their business activities. Such entities may be regarded as consumers if they have micro-enterprise status and if this provision has been transposed into domestic legislation. The non-professional customer is sometimes labelled as 'retail customer' as set out in Article 4 section 1(11) of the Directive 2014/65/EU. The definition appearing in that legislative act is wide, covering any entity which is not a professional customer and for which a specific brokering service is provided.

There is a growing tendency to enlarge the group of subjects eligible for special protection on the financial market. In many ways, the notion of "consumer" is too narrow. Restricting protections only to natural persons denies it to organizational entities having no legal personality and to legal persons, even those that are not involved in business activity. Also, consumer protection is unavailable to a non-professional natural person if the act at issue was made in connection with business or gainful activities conducted by him/her. In this way, consumer protection excludes a group of subjects, in which the information asymmetry is analogous to that seen in consumers. At the same time, the effects of inadequate protection may equally severe for the financial system and its stability. This argues for widespread protection not only of consumers but also of every non-professional customer.

\subsection{Professional customer}

The Directive 2014/65/EU defines a professional customer as an entity for which at least one of the services stipulated in the Directive's Annex is or is to be provided, having the experience and knowledge that allow making informed investment decisions and assessing the associated risk. This definition can be extended to cover the entire financial market by analogy. Accordingly, a professional customer may be considered to be an entity having 
sufficient experience and knowledge to make correct and informed decisions on the financial market with respect to purchased products and services. He can also evaluate all factors contributing to transaction risk and correctly judge the consequences of his decisions.

\section{Institutional protection of consumer}

One of the major challenges now facing the modern financial market is to establish a system of institutional safeguards to ensure security for all market entities and to enforce fair play. However, even the best provisions of substantive law, though necessary, may prove to fall short. Therefore, there is a pressing need for strong and competent state and international institutions duly equipped with auditing and supervisory powers to deal with the present situation. They should also have the possibility of enforcing substantive laws in a way that allows for flexible responses to any emerging threat to the protected values. Pre-crisis supervision did not focus on customer protection on the financial market. At the time, concern for the correct operation of supervised institutions meant that customer rights were addressed only indirectly.

The new supervisory architecture designed to prevent crises has produced a more prestigious model of oversight of the financial market, also where this relates to customer protection. Supervision - in its broad sense - is starting to take a more careful interest in services by verifying them for their suitability for customer needs and legality (especially where this relates to unlawful clauses) [Law 2018]. This is consistent with the expectations of society at large who tends to blame the state or supervisory institutions for any wrongdoing on the financial market. The earlier models of oversight addressed financial market sectors, taking either a sectoral or integrated approach [Buttigieg 2013]. In the "twin peaks" model, it is understood that protecting the market from destabilization and customer protection might be at odds with each other. This means that responsibility for the two should not lie with the same body. In many cases, state authorities, rather than directly applying the "twin peaks" model, will opt to establish public institutions authorized to supervise services offered to customers on the financial market. Their activity is designed to provide a measure of protection to consumers on the financial market who, by being less knowledgeable about the financial market and financial services, are the weaker party. 
Financial supervision is still predominantly nationally based in the European Union. The process of financial integration has initiated an evolutionary approach to financial supervision at the EU level [Schoenmaker 2012]. Rather than moving to a 'holistic', crosssectoral regime such as the 'twin peaks' model, the post-crisis reform simply upgraded the previous supervisory colleges to EU cross-sectoral problems and risks that are evolving, may fail to adequately agencies, resulting in the three sectoral bodies. Financial service consumer protection is supported by the European Banking Authority (EBA), European Insurance and Occupational Pensions Authority (EIOPA) and European Securities and Markets Authority (ESMA). These are empowered to pursue analytical activities to survey consumer trends, cooperate for better standards of transparency, co-ordinate financial education of consumers, initiate restrictions with respect to trading certain financial products and solve inter-sectoral problems. Consumer protection is demonstrated by offering soft-law guidelines, recommendations and warnings to establish models of conduct for supervised institutions and objectives in consumer protection. The major risk of such a sectoral architecture is that separate agencies may fail to recognise any crosssectoral problems and risks that are evolving, may fail to adequately address financial conglomerates, and may more generally encounter fundamental challenges in adopting a more holistic approach to financial regulation and supervision (Ringe, Morais, Munoz 2019).

\section{Conclusions}

The crisis begun in 2007 has shown numerous irregularities in the operation of the financial system, particularly in the banking and insurance sectors. The result was a loss of customer confidence and undermining of the reputation of banks as public confidence institutions. That is why one of the principal directions of efforts to overcome the crisis was, besides liquidity support, to help rebuild trust in the financial system. Trust is one of the cornerstones of a stable financial market. The European financial market can be said to be stabilised after last crisis. There are problems with it, however, related not only to its functioning but also to violating customer (consumer) rights. The victims include not only financially uneducated people but also economists and lawyers with wide expertise in the field. There appear potential dangers to the stability of the entire financial system, arising from a lack of appropriate customer protection.

There is an increasingly visible tendency to extend the group of financial market entities to be covered under special protection. The notion of 'consumer' is, in many areas, 
insufficient. Where protection is limited to natural persons, it is denied to organizational units without legal personality or legal persons even though they might not engage in business activities. Additionally, a non-professional natural person is not protected by consumer law if the offending act took place in connection with that person's business activities. Therefore, protective coverage leaves out a sizeable number of entities whose information asymmetry is analogous to that of consumers. At the same time, failure to provide proper protection for these entities may have equally disastrous effects for the financial system and its stability. As a result, it is becoming an increasingly common idea that not only consumers but all non-professional customers should be protected. The idea is becoming widespread that the weaker party to a legal transaction can be not only a consumer [natural person] but also a non-professional market entity. Such a solution is certainly appropriate. Narrowing down the 'consumer' to a natural person is artificial and out of line with market realities, not to mention the serious consequences of bad financial decisions.

Proper institutional supervision is playing an increasingly important role for proper customer protection. There is a pressing need for strong and competent cooperation among state and international institutions. Their responsibility is not only for ensuring that the supervised entities operate correctly, but also for the quality of services that they provide. 


\section{References}

Akinbami F., Financial services and consumer protection after the crisis, International Journal of Bank Marketing, Vol. 29, 2011

Arner D. W., Barberis J.N., Buckley R.P., FinTech, RegTech and the Reconceptualization of Financial Regulation, Northwestern Journal of International Law \& Business, Forthcoming, University of Hong Kong Faculty of Law Research Paper No. 2016/035, 2016

Benohr l., Private Autonomy and Protection of the Weaker Party in Financial Consumer Contracts: an EU and International Law Perspective, European Law Reviev, no. 43, 2018

Canova T.A., Financial Market Failure as a Crisis in the Rule of Law: From Market Fundamentalism to a New Keynesian Regulatory Model, Harvard Law \& Policy Review, Vol. 3, 2009

Ciacchi A. C., Freedom of contract as freedom from unconscionable contracts, in: M. Kenny, et al. (ed.), Unconscionability in European Private Financial Transactions: Protecting the Vulnerable, Cambridge: Cambridge University Press, 2010

Cyman D., Consumers Protection In The Area Of Loans Indexed To Foreign Currency, in: Radvan M., Gliniecka J., Sowiński T., Mrkývka P. (eds.), The financial law towards challenges of the XXI century: (conference proceedings), Brno: Masaryk University, 2017

Law S., The Transformation of Consumer Law in Times of Crisis: The Ex Officio Control of Unfair Contract Terms, Transformation of Civil Justice: Unity and Diversity, lus GentiumComparative Perspectives on Law and Justice, no. 70, 2018

Lefevre A., Chapman M., Behavioural economics and financial consumer protection, OECD Working Papers on Finance, Insurance and Private Pensions, No. 42, OECD Publishing, Paris; UN Manual on Consumer Protection, Advance Copy 2016

Lui A., Lamb G. W., Artificial intelligence and augmented intelligence collaboration: regaining trust and confidence in the financial sector, Information \& Communications Technology Law, vol. 27, 2018

Mak V., Braspenning J., Errare Humanum Est. Financial literacy in European Consumer Credit Law, TISCO Working Paper Series on Banking, Finance and Services no. 01, 2012

Moloney N., Financial market governance and consumer protection in the EU, in: Faia A., Hackentahl A., Haliassos M., Langenbucher K. (eds), Financial Regulation: A Transatlantic Perspective, Cambridge: Cambridge University Press, 2015

Ramsey I., Changing Policy Paradigms of EU Consumer Credit and Debt Regulation, in: Weatherill S., Leczykiewics D. (eds), The Images of the Consumer in EU Law: Legislation, Free Movement and Competition Law, Oxford: Hart, 2015

Ringe W. G., Morais L. S., Muñoz D. R., A Holistic Approach to the Institutional Architecture of Financial Supervision and Regulation in the EU, Oxford Legal Studies Research Paper No. 56/2019, 2019

Rösler H., Protection of the Weaker Party in European Contract Law: Standardized and Individual Inferiority in Multi-level Private Law, European Regulatory Private Law, vol. 4, 2010

Rutledge S. L., Consumer Protection and Financial Literacy, World Bank Policy Research Working Paper No. 5326, 2010

Schinasi G. J., Defining Financial Stability, IMF Working Papers 2004, WP/04/187, 2004

Schoenmaker D., Financial Supervision in the UE, in: Caprio, G. (ed.), Handbook of Safeguarding Global Financial Stability: Political, Social, Cultural, and Economic Theories and Models, London: Elsevier 2012

\section{Legal Acts}

Council Directive 93/13/EEC of 5 April 1993 on unfair terms in consumer contracts, OJ L 95

Directive 2005/29/EC of the European Parliament and of the Council of 11 May 2005 concerning unfair business-to-consumer commercial practices in the internal market and amending Council Directive 84/450/EEC, Directives 97/7/EC, 98/27/EC and 2002/65/EC of the European Parliament and of the Council and Regulation (EC) No 2006/2004 of the European Parliament and of the Council, OJ L 149

Directive 2008/48/EC of the European Parliament and of the Council of 23 April 2008 on credit agreements for consumers and repealing Council Directive 87/102/EEC, OJ L 133

Directive 2011/83/EU of the European Parliament and of the Council of 25 October 2011 on consumer rights, amending Council Directive 93/13/EEC and Directive 1999/44/EC of the 
European Parliament and of the Council and repealing Council Directive 85/577/EEC and Directive 97/7/EC of the European Parliament and of the Council, OJ L 304

Directive 2014/65/EU of the European Parliament and of the Council of 15 May 2014 on markets in financial instruments and amending Directive 2002/92/EC and Directive 2011/61/EU, OJ L 173

Directive 2014/92/EU of the European Parliament and of the Council of 23 July 2014 on the comparability of fees related to payment accounts, payment account switching and access to payment accounts with basic features, OJ L 257

\section{Other Official Documents}

European Parliamentary Research Service, Consumer protection in the EU, Brussels 2015 FSB, Consumer Finance Protection with particular focus on credit, Basel 2011

OECD, Financial Literacy and Consumer Protection: Overlooked Aspects of the Crisis, OECD Recommendation on Good Practices on Financial Education and Awareness Relating to Credit, 2009 